\title{
ICMS Ecológico: viabilidade de sua utilização a partir do passivo ambiental gerado pela FIOL
}

\author{
Ecological ICMS: feasibility of its use from the environmental liability generated by FIOL \\ ICMS ecológico: viabilidad de su uso a partir de la responsabilidad ambiental que genera FIOL
}

Rivaldo Ribeiro Sobral Neto

ORCID: https://orcid.org/0000-0002-2680-2322 Universidade Católica do Salvador, Brasil E-mail: rivasobral@gmail.com

Amilcar Baiardi

ORCID: https://orcid.org/0000-0001-6087-5296 Universidade Católica do Salvador, Brasil E-mail: amilcar.baiardi@pro.ucsal.br

\begin{abstract}
Resumo
O presente estudo busca avaliar o potencial do ICMS Ecológico (ICMS-E), como instrumento de política pública para os municípios afetados pela construção da Ferrovia de Integração Oeste-Leste (FIOL). Este trabalho possui caráter exploratório, de abordagem quali-quantitativa, tendo como foco um grupo de municípios baianos. Fundamenta-se na Constituição Federal, no Código Tributário Nacional, na Legislação Ambiental e nas Leis Estaduais. Com base em uma análise comparativa, visa estimar se os modelos de arrecadação do ICMS-E adotados pelos estados de Tocantins e Pernambuco se aplicam à Bahia. Investiga-se no contexto da inserção da FIOL, a interface da mesma com os recursos naturais e a destinação de todos os resíduos resultantes das intervenções. Avalia-se que a e temática é de grande relevância, visto que a proteção ambiental é uma preocupação global. Observou-se que a possível implementação do ICMS-E na Bahia poderia representar uma arrecadação superior a 255 milhões de reais, para os municípios baianos influenciados pela FIOL, entre os anos 2016 e 2020. Finalizando o artigo sugere que a implementação do ICMS-E na Bahia poderá ser uma alternativa viável para reverter o passivo ambiental gerado pela FIOL, constituindo-se mais um instrumento de proteção da biodiversidade.
\end{abstract}

Palavras-chave: FIOL; ICMS Ecológico; Resíduos sólidos; Meio ambiente.

\begin{abstract}
This study seeks to assess the potential of the Ecological ICMS (ICMS-E), as a public policy instrument for municipalities impacted by the construction of the West-East Integration Railway (FIOL). This work has an exploratory character, with a quali-quantitative approach, focusing on a group of municipalities in Bahia. It is based on the Federal Constitution and in the National Tax Code, environmental legislation and state laws. Based on a comparative analysis, it aims to estimate whether the ICMS-E collection models for the states of Tocantins and Pernambuco are applied to Bahia. It investigates in the context of FIOL's insertion, its interface with natural resources and the destination of all waste resulting from the interventions. It is estimated that the e thematic is of great relevance, since environmental protection is a global concern. It was observed that the possible implementation of ICMS-E in Bahia could represent a tax collection in excess of 255 million reais, for municipalities in Bahia influenced by FIOL, between 2016 and 2020. Finally, the article suggests that the implementation of ICMS-E in Bahia it may be a feasibility alternative to reversing the environmental liability generated by FIOL, constituting yet another instrument for protecting biodiversity.
\end{abstract}

Keywords: FIOL; Ecological ICMS; Solid waste; Environment.

\section{Resumen}

Este estudio busca evaluar el potencial del ICMS Ecológico (ICMS-E), como un instrumento de política pública para los municipios afectados por la construcción del Ferrocarril de Integración Oeste-Este (FIOL). Este trabajo tiene un carácter exploratorio, con enfoque quali-cuantitativo, focalizado en un grupo de municipios de Bahía. Se basa en la Constitución Federal, en el Código Fiscal Nacional, en la Legislación Ambiental y en las lLeyes de los estados. Con base en un análisis comparativo, tiene como objetivo estimar si los modelos de recolección ICMS-E para los estados de Tocantins y Pernambuco se aplican a Bahía. Investiga en el contexto de la inserción de FIOL, su interfaz con los recursos naturales y el destino de todos los residuos resultantes de las intervenciones. Se estima que la temática es de gran relevancia, ya que la protección del medio ambiente es una preocupación mundial. Se observó que la posible implementación del ICMS-E en Bahía podría representar una recaudación de más de 255 millones de reales, para los municipios de Bahía influenciados por FIOL, entre 2016 y 2020. Finalmente, el artículo sugiere que la 
implementación del ICMS-E en Bahía puede ser una alternativa viable para revertir la responsabilidad ambiental generada por FIOL, constituyendo un instrumento más para proteger la biodiversidad.

Palabras clave: FIOL; ICMS ecológico; Residuo sólido; Medio ambiente.

\section{Introdução}

A degradação do meio ambiente é uma preocupação global que desperta Estados nação e aproxima a sociedade sobre a temática, revelando e conscientizando a população sobre as consequências e a importância da conservação, bem como as mudanças de atitudes em prol da regeneração da biodiversidade.

Remontando a uma síntese histórica acerca dos avanços em defesa dos recursos ambientais, no caso do Brasil, afora os aconselhamentos e iniciativas durante o império da parte de José de Bonifácio e Pedro II, é possível apontar a gênese dessa política com criação do Conselho Florestal Brasileiro (CFB), em 1934, que teve a finalidade de normatizar o uso das florestas (Borges et al., 2009). Internacionalmente, o marco de maior relevância foi a criação do Clube de Roma, no ano de 1968, o qual levantou preocupações acerca da crise e o futuro da humanidade, ensejando que, em 1972, fosse elaborado o relatório intitulado de "Os Limites do Crescimento", o qual se fundamentava na interação do homem e o meio ambiente. Neste documento, assevera-se a preocupação com o crescimento populacional e o esgotamento dos recursos naturais. No mesmo ano, ocorreu a primeira conferência mundial entre o homem e a natureza, intitulada de Conferência de Estocolmo, a qual se propôs conceber um plano de ação para a proteção do meio ambiente. Posteriormente, aconteceu a Convenção de Berna, objetivando regular a vida selvagem e os habitats naturais na Europa.

Outro marco no Brasil foi a instituição da Política Nacional do Meio Ambiente (PNMA), através da Lei n. 6.938, de 31 de agosto de 1981, prevendo a descentralização das ações e transferindo para os estados e os municípios a responsabilidade na aplicação de medidas para a proteção ambiental. Por sua vez, no ano de 1987, deu-se a publicação do Relatório Brundtland o qual consolidou a expressão "desenvolvimento sustentável”, conceito que nasce no pensamento econômico como evolução da diferenciação do conceito de crescimento (Baiardi \& Teixeira, 2010). A Constituição Federal Brasileira de 1988, estabeleceu os princípios da política nacional do meio ambiente.

Tendo como pano de fundo este histórico, o presente artigo buscou tratar da relevância do meio ambiente para a promoção do desenvolvimento socioeconômico sustentável, propondo uma solução viável para compensar o passivo ambiental decorrente da construção da Ferrovia de Integração Oeste-Leste (FIOL), que inicia em Ilhéus/BA e finda em Figueirópolis/TO.

Historicamente, o uso de ferrovias como modal de transporte tem seu início na Inglaterra no século XIX com a necessidade de melhorar a circulação de seus produtos dentro de seu território (Tischer, 2018). Diante do aumento da produção industrial e expansão das cadeias produtivas atreladas à demanda por produtos, os países europeus passaram a necessitar de um meio de transporte que auxiliasse seu crescimento e, consequentemente, a distribuição mais efetiva dos produtos fabricados.

Todavia, somente em 1829, através de George Stephenson, foi possível a criação da primeira locomotiva a vapor. Daí em diante novas tecnologias surgiram até os grandes avanços, tal como os trens de alta velocidade, denominados TGVs. Esse modelo de transporte possibilitou o encurtamento entre pessoas e mercados, gerando maior distribuição das mercadorias produzidas nas fabricas.

O Brasil, segundo a Associação Nacional dos Transportadores Ferroviários (ANTF, 2021), possui 30,75 mil quilômetros de ferrovias, com área de 8,52 milhões $\mathrm{km}^{2}$ e ainda apresenta baixa densidade da malha se comparado a países de dimensões continentais, como Canadá, Índia e China, e mesmo diante de seus pares na América Latina, como México e Argentina.

Diante deste modelo de transporte barato e eficiente para grandes distâncias, revela-se interessante buscar novos investimentos, pois a melhoria dos transportes de carga no país possibilitará a dinamização da economia e com ela o aumento 
da arrecadação de impostos, especificamente o Imposto sobre Circulação de Mercadorias e Serviços e sobre prestações de serviços de transporte interestadual, intermunicipal e de comunicação (ICMS).

Acerca dessa temática, a Constituição da República Federativa do Brasil (Brasil, 1988) normatiza que o ICMS arrecadado pelo estado deve ser repassado em $25 \%$ aos municípios e, desse valor recebido, $1 / 4$ ou $25 \%$ poderá ser utilizado em critérios ambientais, através de uma lei estadual. Tal critério se baseia no princípio do protetor-recebedor, no qual o agente público ou privado que proteger um bem natural em benefício de toda comunidade deverá obter uma contrapartida financeira, pela contribuição da atividade a favor da proteção ambiental. Foi com base nessa premissa que 18 estados brasileiros implementaram o ICMS-Ecológico (Sobral \& Reis, 2020).

O referido imposto possui caráter inovador no contexto de políticas públicas ambientais brasileiras, uma vez que somente terá o direcionamento de recursos aos entes municipais, de acordo com suas ações na proteção da natureza. Caso os municípios preservem suas florestas e conservem sua biodiversidade, ganharão uma pontuação maior nos critérios de repasse, auferindo recursos financeiros a título de compensação pelas áreas destinadas à conservação e, ao mesmo tempo, um incentivo para manutenção e criação de novas áreas.

Em relação à proteção da natureza, a construção da Ferrovia de Integração Oeste-Leste (FIOL), poderá criar passivos e ativos, gerando impactos negativos e positivos para o ambiente. Inclusive há estimativas de que a mudança do modal rodoviário para o ferroviário irá reduzir em mais de 38\% da emissão de dióxido de carbono $\left(\mathrm{CO}^{2}\right)$, diminuindo a quantidade de substâncias nocivas lançadas ao meio ambiente.

Segundo o Sindicato Interestadual da Indústria de Materiais e Equipamentos Ferroviários e Rodoviários (SIMEFRE, 2013), o potencial de redução máxima de emissão de dióxido de carbono por ferrovias foi estimado em $37 \%$ em relação às rodovias, muito próximo ao valor médio determinado por estudo similar realizado pela VLI, em $38 \%$.

Diante disso, é notório que a construção da FIOL vai gerar um passivo ambiental, porém haverá um relevante ativo ambiental concernente à redução de carbono em decorrência da diminuição de fluxos de caminhões. Decerto que das obras da FIOL sobrevirão outros passivos ambientais que poderão ser compensados com maior agilidade, na eventualidade de se dispor de recursos gerados em decorrência de danos aos ecossitemas. A exemplo do que ocorre com as receitas oriundas do ICMS-E, já instituído por dezoito entes federados, tal recurso poderia ser utilizado em prol da recuperação de latentes danos ambientais provenientes da construção da FIOL, desde que haja vontade legislativa para implementá-la.

O presente texto tem como objetivo avaliar o potencial de geração do ICMS Ecológico (ICMS-E), visto como instrumento de política pública voltado para os municípios afetados pela construção da Ferrovia de Integração Oeste-Leste (FIOL). Embora o empreendimento da FIOL ainda não esteja em operação, antecipa-se sobre a temática, objetivando uma alternativa para ampliar a receita dos municípios que serão impactados pela ferrovia, diante dos prováveis danos causados. Portanto, foi desenvolvido em caráter simulatório, os cálculos do ICMS-E e os resultados serão apresentados na sequência.

\section{Metodologia}

Este artigo se situa em termos de classificação ou taxonomia, no ramo da Política Pública de equilibrio fiscal que, em Bobbio et al., (2004, p. 404) é abordado no verbete Estado Contemporâneo, item V, Estado Fiscal. Segundo Bobbio et al., (2004) se no Estado absoluto a riqueza do Estado e a riqueza dos detentores do poder se confundiam, no Estado contemporâneo e constitucional, Estado e propriedade se separam, criando a dependência fiscal do Estado em relação à sociedade.

Para Mendes (2008), o equilíbrio fiscal deve ser visto à luz da racionalidade orçamentária e não pode ser entendido como tendo um efeito de perda de apoio político. Esclarecimentos e contrapesos devem ser aduzidos para que um esforço arrecadatório não seja visto como uma "sanha arrecadatória" (Galeski, 2007). 
De acordo com Rêgo (2013), é imprescindível demonstrar a importância do equilíbrio fiscal para a gestão pública, fazendo-se necessário pôr em destaque a qualidade do gasto público, a partir da aplicação ou aperfeiçoamento de instrumentos de arrecadação. A administração das finanças públicas deve buscar incessantemente um ajuste fiscal entre receita e a despesa pública, e ter a preocupação de comunicar que os novos recursos serão utilizados tanto para corrigir eventuais desequilíbrios entre a arrecadação de receita e o dispêndio da mesma, como para custear investimentos visando melhora o padrão de vida da população. No caso específico se pode acrescer visar também a proteção do ambiente.

Como investigação tem caráter exploratório com abordagem quali-quantitativa, tendo como foco um grupo de municípios baianos. O material ou objeto se constitui da legislação existente e de todos os dados disponíveis que têm como fonte as estatísticas oficiais, os estudos temáticos e o Relatório de Impacto Ambiental, o RIMA. A pesquisa exploratória é usada em casos nos quais é necessário definir o problema com maior precisão, identificar cursos relevantes de ação ou obter dados adicionais antes que se possa desenvolver uma abordagem (Gil, 2002; Malhotra, 2001).

Neste cenário, o ensaio discerniu as literaturas temáticas, remontando a história até o tempo atual, propiciando pesquisa bibliográfica versando sobre meio ambiente, desenvolvimento, política pública fiscal e direito ambiental. Ademais, foram feitas descrições de análises estimativas e comparativas, respectivamente, nos estados da Bahia, de um lado, e Pernambuco e Tocantins, de outro, referente ao ICMS-E, tendo como base de consulta a Constituição Federal e a Legislação Tributária.

Destarte, os dados concretos foram fundamentados pelas Constituições Estaduais, Constituição Federal, Relatório de Impacto Ambiental da Ferrovia Oeste-Leste (RIMA), Código Tributário Nacional, Instituto Brasileiro de Geografia e Estatística (IBGE), Conselho Nacional do Meio Ambiente (CONAMA), Instituto do Meio Ambiente e Recursos Hídricos (INEMA), Confederação Nacional dos municípios (CMN).

Ademais, para realização da estimativa de possível arrecadação do ICMS-E para os municípios baianos afetados pela FIOL, como também os valores recebíveis de ICMS- E dos estados em estudo, procederam-se levantamentos com base nas referências do Tribunal de Contas dos Estados (TCE), Secretaria da Fazenda dos Estados (SEFAZ). Foram utilizadas referências do ano de 2016 até 2020, identificando os 55 municípios baianos da FIOL que mais se beneficiariam com a implementação do ICMS-E, bem como apresentou-se a arrecadação dos 16 municípios de Tocantins, estado que já instituiu este instrumento de política pública.

\section{Contextualização do Objeto}

\subsection{Ferrovia de Integração Oeste- Leste (FIOL)}

A construção da Ferrovia Oeste-Leste (FIOL), inequivocamente fomentará o crescimento e o desenvolvimento econômico dos municípios baianos e tocantinenses envolvidos no seu traçado, mas, como está previsto, provocará também reflexos no âmbito nacional.

Consoante o Relatório de Impacto Ambiental (RIMA), a FIOL apresenta uma imensa importância estratégica para o desenvolvimento nacional, pois, com ela serão obtidos: maior competitividade dos produtos brasileiros no exterior; menores custos dos produtos comercializados no mercado interno; incentivo aos investimentos, à modernização e à produção, contribuindo para os aumentos da renda e do emprego na região (Ministério dos Transportes, 2009b).

Assim, a construção da FIOL propiciará trocas de cargas do oeste, centro e leste do país, permitindo a sua integração ao modal ferroviário nacional, o que ensejará, quando viável, a mudança do transporte rodoviário pelo ferroviário. Inclusive, quando comparados estes modais, o ferroviário possibilita maior redução na emissão de $\mathrm{CO}^{2}$ no meio ambiente, como já externado. 
Neste cenário, a Constituição Federal, ao tratar da questão ambiental, propiciou um mecanismo para que os estados viabilizassem a criação de um instrumento de política pública dentro de um imposto já existente, o ICMS, que colaborasse efetivamente na conservação ambiental, possibilitando o incremento nas verbas municipais, sem reverberar em novos tributos. Este imposto foi intitulado por alguns entes federados de ICMS Ecológico.

O presente artigo orbita pela viabilidade deste mecanismo para remediação do passivo ambiental gerado pela construção da FIOL, porquanto sua implantação, como todo e qualquer empreendimento, gerará impactos ambientais, positivos ou negativos, visto que se relaciona com alterações do ambiente por ação antrópica.

Segundo o CONAMA,

considera-se impacto ambiental é qualquer alteração das propriedades físicas, químicas e biológicas do meio ambiente, causado por qualquer forma de matéria ou energia resultante das atividades humanas que, direta ou indiretamente, afetam:

I - a saúde, a segurança e o bem-estar da população;

II - as atividades sociais e econômicas;

III - a biota;

IV - as condições estéticas e sanitárias do meio ambiente;

$\mathrm{V}$ - a qualidade dos recursos ambientais. (CONAMA apud IMA/AL, 1986).

Por sua vez, não se pode olvidar dos impactos positivos causados pela FIOL, especialmente no campo econômico, através da geração de mais de 39.000 (trinta e nove mil) empregos diretos e indiretos durante a construção e para a manutenção da ferrovia, segundo o RIMA (Ministério dos Transportes, 2009b).

Ademais, a instalação da ferrovia possibilitará o aquecimento do mercado interno com a diminuição dos custos de produção, maior competitividade e aumento da produção dos produtos baianos, propiciando a diminuição de acidentes, quando comparado com as rodovias (Ministério dos Transportes, 2009b).

A Figura 1, em consonância ao RIMA exibe mapa dos 55 municípios baianos que terão suas áreas direta ou indiretamente afetadas, por decorrência da construção da ferrovia. Pode-se observar a distribuição espacial dos municípios na cor amarela em destaque e o traçado da FIOL na cor vermelha (Ministério dos Transportes, 2009b). 
Figura 1 - FIOL Ferrovia de Integração.

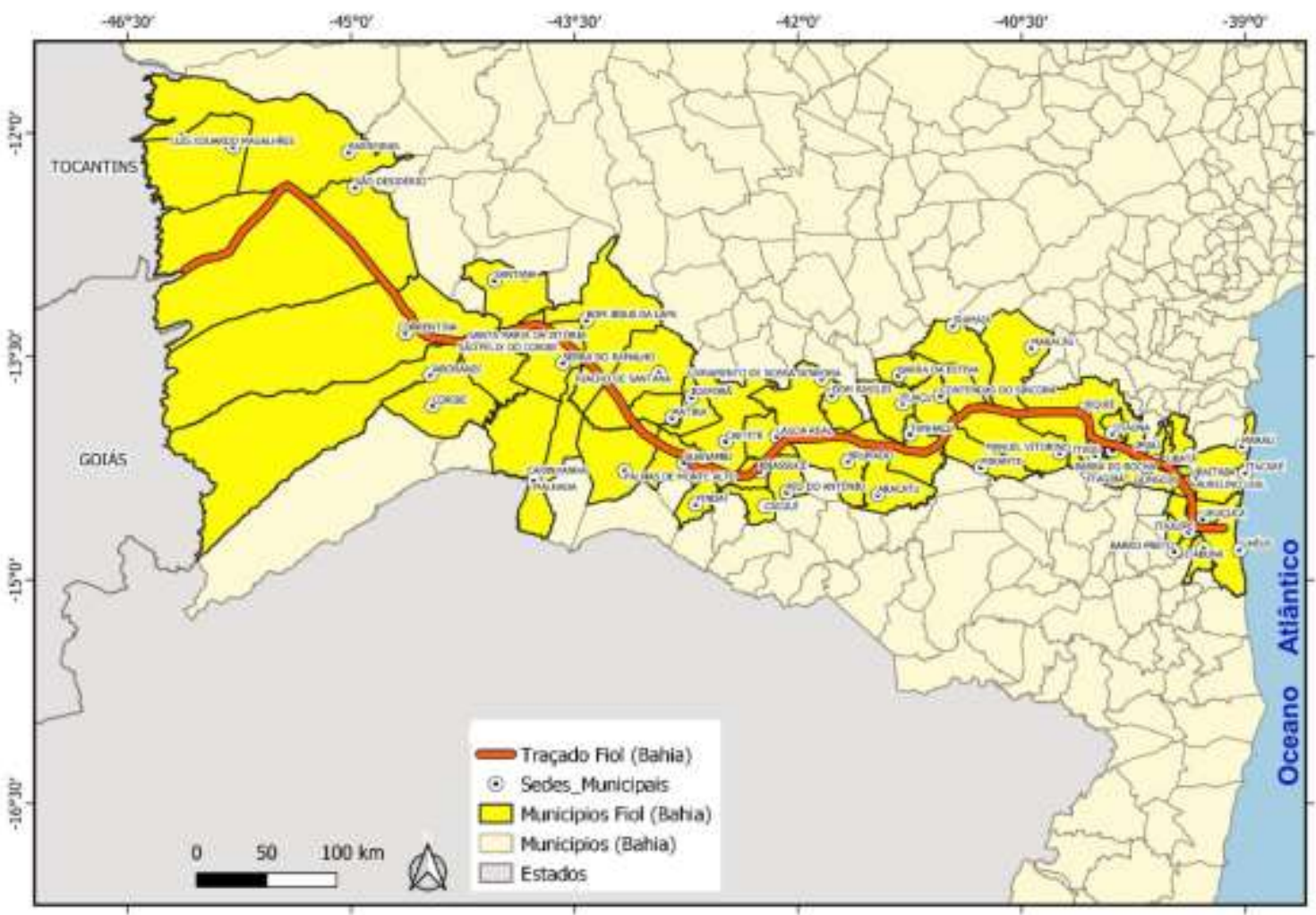

Fonte: RIMA (Ministério dos Transportes, 2009b) e IBGE (2021). Elaboração própria.

Segundo dados do RIMA, os trilhos da ferrovia apresentam uma largura de $80 \mathrm{~m}$, bitola adequada ao estado da arte do desenvolvimento tecnológico ferroviário. As áreas localizadas tanto ao norte como a sul do traçado ferroviário, em grau variável, serão impactadas com ocupação por máquinas e pessoal durante a execução da obra (Ministério dos Transportes, 2009b).

O Quadro 1 apresenta a classificação ferroviária da área em construção. Durante a extensão serão instaladas as malhas férreas contendo materiais como brita, cascalho e saibro para a terraplanagem do solo e correções necessárias para que os trilhos sejam instalados. Para a implementação da ferrovia, que terá apenas uma via, haverá uma movimentação do material de solo para realização de aterramentos e adequações às condições necessárias à instalação dos trilhos. Dessa forma, devido à complexidade do empreendimento, realizou-se uma classificação das áreas afetadas.

Quadro 1 - Classificação Ferroviária da Área em Construção.

\begin{tabular}{|c|c|c|c|}
\hline Classificação & Distância & Localização & Impacto da ferrovia \\
\hline $\begin{array}{c}\text { Área diretamente } \\
\text { afetada }\end{array}$ & $80 \mathrm{~m}$ & Faixa de domínio da ferrovia & Trilho. \\
\hline $\begin{array}{c}\text { Área de influência } \\
\text { direta }\end{array}$ & $10 \mathrm{~km}$ & $\begin{array}{c}\text { Faixa de } 5 \mathrm{~km} \text { de cada lado do eixo } \\
\text { de trilho }\end{array}$ & $\begin{array}{c}\text { Se dá ao longo da via e no âmbito da } \\
\text { influência da construção. }\end{array}$ \\
\hline $\begin{array}{c}\text { Área de influência } \\
\text { indireta }\end{array}$ & $5 \mathrm{~km}$ & $5 \mathrm{~km}$ de distância da ferrovia & $\begin{array}{c}\text { Parte do território atingido ou distância } \\
\text { de até } 5 \mathrm{~km} .\end{array}$ \\
\hline
\end{tabular}

Fonte: RIMA (Ministério dos Transportes, 2009b). Adaptado pelo autor. 
A área de estudo compreende os 55 municípios baianos afetados com a construção da FIOL, além dos outros 16 municípios do estado de Tocantins. O empreendimento inicia em Ilhéus/Ba e finda em Figueirópolis/TO, tendo a extensão de 1.527 quilômetros e objetiva o escoamento de grãos, do oeste baiano e de minério, do sul da Bahia (Caetité e Tanhaçu), servindo, no fluxo contrário, para transportar cargas de interesse da economia do oeste com fertilizantes, corretivos, equipamentos etc. Vislumbra-se também a possibilidade de se unir com a Ferrovia Norte-Sul, de forma a integrar as malhas ferroviárias brasileiras, melhorando a logística de apoio à produção agropecuária, agroindustrial e mineral.

Sobreleve-se que, malgrado o estudo cite todos os municípios integrantes da FIOL (Bahia e Tocantins), o aprofundamento direciona-se às implicações da ferrovia nos municípios baianos. Na Bahia, o traçado da FIOL tem início no município de Ilhéus, onde se localiza a Lagoa Encantada, um dos pontos turísticos da região e de grande relevância ambiental. Como influenciado também pelo segmento inicial da ferrovia se inclui Uruçuca onde está localizado o Parque Estadual Serra do Conduru, um dos maiores parques ecológicos de grande diversidade florística e faunística do Brasil, em razão da contiguidade da composição da vegetação que se estende entre Itacaré e Ilhéus. A região é cercada por fazendas e matas nativas apresentando uma beleza incomparável, predominando áreas baixas, alagadas e com formação de brejos, sendo alimentada por diversos ribeirões. Na mesma localizam-se os povoados Laranjeiras Velha, Urucutuca, Campinhos e o distrito de Sambaituba, em cujo entorno observa-se o predomínio da Mata Atlântica de origem secundária, com densidade de vegetação rica em diversidades faunística e florística. Nessa localidade predomina o cultivo do cacau na modalidade de sistema agroflorestal tipo "cabruca", cujo principal produto é amêndoa destinada à fabricação do chocolate (Santos, 2004).

O Parque Estadual Serra do Conduru foi instituído pelo Decreto Estadual no 6.227 de 21 de fevereiro de 1997 e ampliado pelo Decreto Estadual no 8.702 de 04 de novembro de 2003. A reserva apresenta floresta do tipo Ombrófila Densa, sendo uma das maiores áreas de preservação ambiental em biodiversidade, conservada até então. De acordo com o INEMA (2021), o parque apresenta 458 espécies diferentes de árvores por hectare, um dos maiores índices de endemismo do mundo, sendo um dos mais importantes remanescentes florestais da costa do nordeste brasileiro. As áreas com suporte de vegetação são de suma importância para a manutenção dos recursos hídricos da região no abastecimento de água.

\subsection{Breve descrição dos biomas envolvidos}

O Estado da Bahia apresenta três biomas em seu território, a saber: Mata Atlântica, Cerrado e Caatinga. A Mata Atlântica apresenta uma área de 1.306 .000 quilômetros quadrados, correspondente a 15\% do território nacional, sendo a segunda maior floresta do Brasil. A grande extensão territorial do bioma marca sua importância no contexto nacional em virtude da maior riqueza em biodiversidade, solo, clima e vegetação. É considerado o mais rico de todos, por apresentar uma biodiversidade rica em espécies endêmicas (Rios \& Thompsom, 2013).

A importância da Mata Atlântica é revelada devido a existência de espécies endêmicas, por estar isolada das outras florestas, e ser um dos biomas mais diversificados do Brasil. Neste cenário, os municípios pertencentes ao traçado da FIOL, apresentam a vegetação com a cobertura dos três biomas que compõem a Bahia, que são: Mata Atlântica, Cerrado e Caatinga.

No Cerrado, bioma considerado o segundo maior da América do Sul, apresenta 2.036.448 quilômetros quadrados de área, perfazendo $24 \%$ do território nacional. Está presente no Centro-Oeste, Nordeste e Norte, ocupando totalmente o Distrito Federal, boa parte de Goiás, Tocantins, Mato Grosso do Sul, Maranhão e Minas Gerias, entre outros estados com menor área ocupada (Rios \& Thompsom, 2013). Muitos entes federados apresentam na sua formação vegetal a presença do bioma Cerrado. Neste cenário, a Bahia é considerada um deles, tendo a parte oeste do estado com maior predominância.

Em relação à Caatinga, os doutrinadores defendem ser exclusivo típico brasileiro, com características peculiares na vegetação. Consoante Rios e Thompsom (2013), esse bioma apresenta flora e fauna com riqueza de endemismo, ocupando a maior parte do Nordeste e a Bahia com mais da metade de seu território inserido nele. 
Segundo Baiardi (2015) o bioma da Caatinga na Bahia abrange o ecossistema altitudes, o qual está geograficamente definido pelas terras altas que constituem a Chapada Diamantina, o Planalto de Conquista e seus contrafortes mais expressivos, tanto a oeste como a leste.

\section{Implementação do ICMS Ecológico no Brasil}

Na contemporaneidade a maioria dos estados brasileiros já utilizam o ICMS-E como instrumento de política pública em prol da biodiversidade. Em relação à distribuição a Figura 2 demonstra os percentuais destinados a cada ente federativo na arrecadação do ICMS-E no Brasil, variando de $1 \%$ até $13 \%$. O estado de Tocantins, que é contemplado no traçado FIOL, foi o ente que destinou o maior percentual dos recursos do ICMS-E para proteção ambiental, com $13 \%$.

Figura 2 - Repasses de ICMS-E no Brasil.

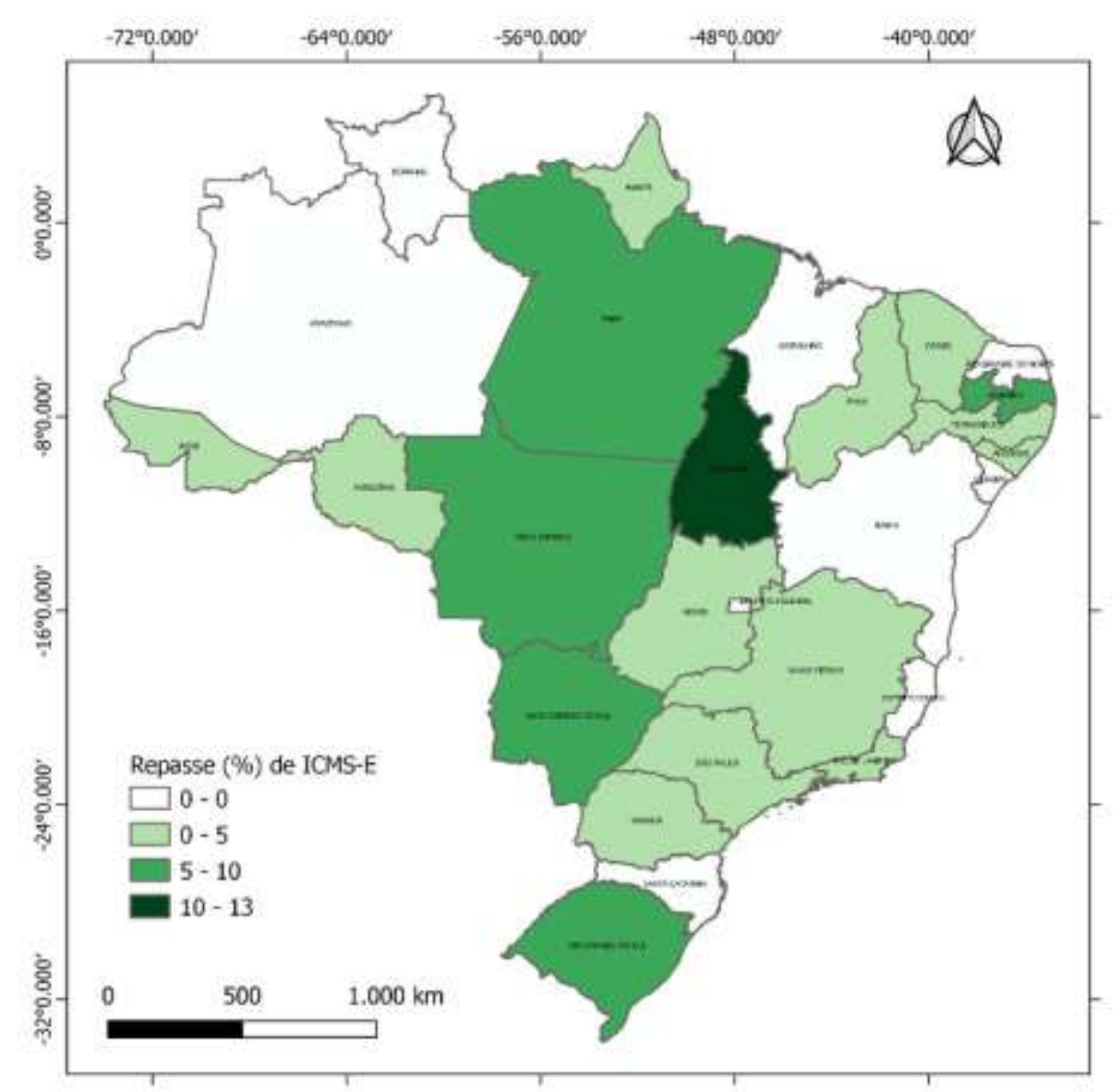

Fonte: IBGE (2021), SEFAZ/BA (2021) e TCE-PE (2021b). Nota: Elaboração própria.

No Brasil, dos 26 estados da federação, 18 (69,2\%) destes já instituíram o ICMS-E, que são: Alagoas, Acre, Amapá, Ceará, Goiás, Mato Grosso do Sul, Mato Grosso, Minas Gerais, Paraíba, Paraná, Pernambuco, Piauí, Rio de Janeiro, Rio Grande do Sul, Rondônia, São Paulo, Pará e Tocantins. Apenas não implementaram, os estados do Amazonas, Bahia, Espírito Santo, Maranhão, Rio Grande do Norte, Roraima, Santa Catarina e Sergipe (Sobral \& Reis, 2020). Neste cenário, o ICMS Ecológico está presente no ordenamento jurídico da maioria dos estados brasileiros, em alguns destes por mais de duas décadas, a exemplo da iniciativa pioneira do estado do Paraná, que surgiu pela imposição dos seus municípios quando vivenciavam prejuízos econômicos, em detrimento das limitações no uso do solo, como também por incorporarem a Unidades de Conservação. Diante disso, requereram uma compensação financeira para fomentarem o desenvolvimento econômico. Assim, ao longo dos anos o ICMS-E tornou-se modelo nacional. 


\subsection{Viabilidade do ICMS-E na Bahia}

O ICMS-E é um instrumento de política pública tributária, presente em 18 estados brasileiros, que poderá propiciar um incremento nas verbas municipais dos municípios afetados pela construção da FIOL, desde que participem efetivamente na proteção ambiental, buscando diminuir o passivo ambiental.

Insta destacar que a negligência presente ampliará o passivo ambiental no futuro, seja diante da ausência no tratamento da poluição gerada, a exemplo do que ocorre com a coleta e destinação do lixo, seja na emissão de gases poluentes, dentre outros. O Estado e a própria sociedade devem criar alternativas para obstar danos irreversíveis para as futuras gerações, visto que a não observância poderá intensificar os problemas ambientais e, consequentemente, poderá em virtude de possível necessidade do Estado, serem instituídos novos tributos ou até mesmo majorados os já existentes.

Consoante a célebre frase do escritor e diplomata americano Benjamim Franklin, do século XVIII, "Só há duas certezas na vida: a morte e os impostos"1. Neste pensamento, é oportuno destacar que o Estado sobrevive substancialmente dos impostos.

Neste cenário, o ICMS-E se apresenta como um auxiliar para atenuar estes latentes danos, sendo um tributo que remunera os municípios que protejam e conservem o meio ambiente dos seus territórios, como também incentiva a promoção de políticas públicas ambientais sem aumentar a carga tributária para os contribuintes, pois não se trata de um novo tributo, e sim de um atual critério ambiental que apenas transfere as receitas pré-existentes.

Assim, a implementação do ICMS-E será imprescindível para o melhor aproveitamento dos benefícios tributários e factível, sobretudo, para promoção do desenvolvimento social e econômico, aliado à proteção da biodiversidade e da qualidade de vida da população impactadas pela construção da FIOL.

\section{Comparação entre a Bahia, Pernambuco e Tocantins}

\subsection{Estimativa do ICMS-E na Bahia e arrecadações de Pernambuco e Tocantins}

Ao tratarmos acerca da arrecadação do ICMS-E nos estados de Pernambuco e Tocantins comparadas a valores estimados de recebimento do ICMS-E na Bahia, no período de 2016 até 2020, resultaram nas magnitudes apresentadas na Tabela 1.

Tabela 1 - Arrecadação de Pernambuco e Tocantins com a estimativa do ICMS-E na Bahia, no período de 2016 até 2020

\begin{tabular}{lllllll}
\hline ESTADO & $\mathbf{2 0 1 6}$ & $\mathbf{2 0 1 7}$ & $\mathbf{2 0 1 8}$ & $\mathbf{2 0 1 9}$ & $\mathbf{2 0 2 0}$ & TOTAL \\
\hline BAHIA & $294.673 .947,50$ & $316.460 .088,25$ & $357.552 .961,93$ & $372.638 .094,01$ & $372.583 .438,83$ & $\mathbf{1 . 7 1 3 . 9 0 8 . 5 3 0 , 5 2}$ \\
PERNAMBUCO & $79.441 .745,41$ & $79.626 .183,58$ & $86.473 .927,90$ & $90.218 .284,64$ & $83.884 .574,00$ & $\mathbf{4 1 9 . 6 4 4 . 7 1 5 , 5 3}$ \\
TOCANTINS & $72.186 .514,96$ & $77.276 .108,33$ & $98.072 .026,38$ & $93.718 .946,77$ & $101.738 .569,41$ & $\mathbf{4 4 2 . 9 9 2 . 1 6 5 , 8 5}$ \\
\hline
\end{tabular}

Fonte: SEFAZ/BA (2021), TCE/PE (2021b) e SEFAZ/TO (2021). Elaboração própria.

O estado da Bahia destaca-se com um valor estimado superior 1,7 bilhões de reais, seguido da arrecadação de ICMSE dos estados de Tocantins com 442 milhões de reais e Pernambuco com 419 milhões de reais, nos últimos 5 anos (2016 até 2020) cumulativamente. A Bahia apresenta o potencial de arrecadação de aproximadamente duas vezes a soma de todo o valor arrecadado nos últimos 5 anos nos estados de Tocantins e Pernambuco.

Por sua vez, a Tabela 2, apresenta a estimativa de possíveis valores do ICMS-E para os 55 municípios da Bahia e arrecadação dos 16 municípios tocantinenses impactados pela FIOL, dispostos pela ordem de maior relevância financeira.

${ }^{1}$ No original: In this world nothing can be said to be certain, except death and taxes! (Franklin \& Franklin, 1817). 
Tabela 2 - Distribuição da estimativa e da arrecadação do ICMS-E nos 71 municípios impactados pela FIOL (Bahia e Tocantins representado em cinza), no período de 2016 até 2020.

\begin{tabular}{|c|c|c|c|c|c|c|}
\hline MUNICÍPIO & 2016 & 2017 & 2018 & 2019 & 2020 & Total $(\mathbf{R} \$)$ \\
\hline LUIS EDUARDO MAGALHÃES & $5.307 .601,96$ & $6.391 .816,38$ & $7.501 .195,69$ & $7.123 .329,60$ & $7.701 .555,33$ & $34.025 .498,96$ \\
\hline SÃO DESIDÉRIO & $4.517 .594,79$ & $5.264 .857,86$ & $5.187 .020,09$ & $5.384 .000,04$ & $7.135 .892,05$ & $27.489 .364,83$ \\
\hline ITABUNA & $4.003 .541,48$ & $4.183 .443,57$ & $4.906 .922,22$ & $5.227 .500,63$ & 4.974.891,91 & 23.296.299,81 \\
\hline BARREIRAS & $3.574 .242,11$ & $4.081 .239,04$ & $4.610 .687,74$ & $4.921 .788,68$ & $5.500 .046,55$ & $22.688 .004,12$ \\
\hline JEQỤIÉ & $3.572 .925,49$ & 3.957.313,56 & $4.500 .039,45$ & $4.754 .837,49$ & $4.719 .736,28$ & 21.504.852,27 \\
\hline ILHÉUS & $3.472 .452,28$ & $3.674 .098,78$ & $4.140 .715,46$ & 4.373.297,19 & $3.799 .285,10$ & $19.459 .848,81$ \\
\hline CORRENTINA & $2.518 .849,31$ & 2.795.295,12 & $3.119 .303,87$ & $3.380 .455,51$ & 4.104.795,78 & $15.918 .699,59$ \\
\hline BRUMADO & $1.298 .345,84$ & $1.442 .403,39$ & $1.754 .144,29$ & $2.169 .376,91$ & $2.451 .272,37$ & $9.115 .542,80$ \\
\hline JABORANDI & $1.086 .804,28$ & $1.211 .107,63$ & $1.226 .593,21$ & $1.359 .925,32$ & $1.606 .164,53$ & $6.490 .594,97$ \\
\hline GUANAMBI & $924.323,63$ & $1.052 .106,28$ & $1.271 .873,56$ & $1.299 .475,30$ & $1.252 .481,28$ & $5.800 .260,05$ \\
\hline BOM JESUS DA LAPA & $787.992,02$ & $893.458,36$ & $1.121 .498,79$ & $1.290 .015,29$ & $1.323 .885,12$ & $5.416 .849,58$ \\
\hline PONTE ALTA DO BOM JESUS/TO & $131.711,80$ & $294.257,54$ & $1.780 .484,27$ & $1.823 .096,52$ & $1.336 .065,05$ & $5.365 .615,18$ \\
\hline CAETITÉ & $927.874,43$ & $997.232,67$ & $998.104,51$ & $981.948,57$ & $963.647,16$ & $4.868 .807,34$ \\
\hline PEIXE/TO & $784.124,51$ & $1.106 .886,84$ & $899.817,12$ & $858.935,37$ & $868.967,02$ & $4.518 .730,86$ \\
\hline GURUPI/TO & $757.840,62$ & $975.235,94$ & $842.392,48$ & $1.080 .496,47$ & $793.274,87$ & 4.449.240,38 \\
\hline MARACÁS & $268.385,65$ & $357.110,67$ & $513.450,43$ & $805.539,17$ & $1.747 .605,44$ & $3.692 .091,36$ \\
\hline LAVANDEIRA/TO & $591.963,28$ & $376.280,78$ & $1.177 .992,65$ & $561.550,30$ & $836.278,84$ & $3.544 .065,85$ \\
\hline ALVORADA/TO & $407.237,60$ & $524.815,69$ & $1.359 .924,87$ & $455.988,76$ & $510.873,74$ & $3.258 .840,66$ \\
\hline PARANA/TO & $262.296,97$ & $561.027,34$ & $748.577,59$ & $758.234,00$ & $858.876,76$ & $3.189 .012,66$ \\
\hline LIVRAMENTO DE NOSSA & $571.519,92$ & $593.677,70$ & $625.234,61$ & $633.026,23$ & $584.202,67$ & $3.007 .661,13$ \\
\hline SANTA MARIA DA VITÓRIA & $404.666,25$ & $418.540,95$ & $467.221,48$ & $502.800,86$ & $497.572,81$ & $2.290 .802,35$ \\
\hline IPIAÚ & $412.433,49$ & $433.588,77$ & $479.184,14$ & $472.378,84$ & $450.742,25$ & $2.248 .327,49$ \\
\hline TAIPAS DO TOCANTINS/TO & $429.516,49$ & $391.513,64$ & $390.660,25$ & $482.879,53$ & $385.036,67$ & $2.079 .606,58$ \\
\hline SUCUPIRA/TO & $127.379,38$ & $149.127,73$ & $608.285,01$ & $705.443,20$ & $479.771,65$ & $2.070 .006,97$ \\
\hline FIGUEIRÓPOLIS/TO & $159.273,78$ & $356.634,82$ & $363.831,21$ & $591.457,82$ & $567.083,74$ & $2.038 .281,37$ \\
\hline TAGUATINGA/TO & $305.451,15$ & $332.907,49$ & $132.949,26$ & $520.348,15$ & $670.460,31$ & $1.962 .116,36$ \\
\hline IGAPORÃ & $378.871,07$ & $447.171,50$ & $374.511,93$ & $365.261,51$ & $355.122,02$ & $1.920 .938,03$ \\
\hline ARRAIAS/TO & $442.629,90$ & $324.810,25$ & $355.374,08$ & $305.773,35$ & $473.151,41$ & $1.901 .738,99$ \\
\hline BARRA DA ESTIVA & $303.451,73$ & $345.171,76$ & $402.136,85$ & $403.415,89$ & $405.723,20$ & $1.859 .899,43$ \\
\hline SERRA DO RAMALHO & $291.376,44$ & $315.653,73$ & $377.513,12$ & $420.540,95$ & $422.725,12$ & $1.827 .809,36$ \\
\hline CACULÉ & $303.686,71$ & $335.420,96$ & $384.100,40$ & $399.854,71$ & $394.040,88$ & $1.817 .103,66$ \\
\hline AURORA DO TOCANTINS/TO & $122.895,56$ & $372.610,10$ & $411.445,53$ & $334.325,25$ & $564.127,40$ & $1.805 .403,84$ \\
\hline ITAJUIPE & $342.535,79$ & $317.241,32$ & $372.164,59$ & $398.964,14$ & $370.113,69$ & $1.801 .019,53$ \\
\hline RIACHO DE SANTANA & $304.430,12$ & $329.770,63$ & $368.418,86$ & $379.929,54$ & $379.884,92$ & $1.762 .434,07$ \\
\hline ITAGIBA & $381.930,60$ & $462.321,43$ & $379.795,38$ & $251.402,56$ & $203.111,77$ & $1.678 .561,74$ \\
\hline SANTANA & $285.606,68$ & $288.515,84$ & $335.809,09$ & $361.609,42$ & $359.797,60$ & $1.631 .338,63$ \\
\hline CAMPOS LINDOS/TO & $158.403,76$ & $150.915,37$ & $810.669,40$ & $221.684,74$ & $259.035,55$ & $1.600 .708,82$ \\
\hline NOVO ALEGRE/TO & $157.358,11$ & $319.853,72$ & $346.582,60$ & $385.268,47$ & $349.492,32$ & $1.558 .555,22$ \\
\hline CARINHANHA & $250.971,71$ & $270.398,46$ & $310.924,22$ & $340.363,48$ & $350.960,83$ & $1.523 .618,70$ \\
\hline COMBINADO/TO & $138.996,87$ & $217.685,08$ & $276.815,61$ & $498.324,57$ & $378.758,30$ & $1.510 .580,43$ \\
\hline PINDAI & $159.574,14$ & $178.478,38$ & $298.401,32$ & $420.078,27$ & $451.920,03$ & $1.508 .452,14$ \\
\hline ITACARÉ & $245.654,64$ & $265.534,07$ & $307.308,07$ & $316.725,16$ & $313.741,12$ & $1.448 .963,06$ \\
\hline ITUAÇU & $227.991,01$ & $263.580,90$ & $326.105,63$ & $330.303,53$ & $294.401,08$ & $1.442 .382,15$ \\
\hline SÃO FÉLIX DO CORIBE & $252.502,25$ & $266.162,59$ & $304.704,10$ & $312.937,20$ & $305.055,34$ & $1.441 .361,48$ \\
\hline PALMAS DE MONTE ALTO & $241.769,06$ & $262.205,44$ & $291.051,76$ & $304.512,72$ & $311.219,05$ & $1.410 .758,03$ \\
\hline CORIBE & $240.019,23$ & $258.786,27$ & $298.899,60$ & $309.355,29$ & $287.426,65$ & $1.394 .487,04$ \\
\hline MARAÚ & $239.324,51$ & $260.276,42$ & $312.337,18$ & $305.130,00$ & $269.520,71$ & $1.386 .588,82$ \\
\hline TANHAÇU & $245.702,21$ & $265.526,17$ & $290.452,97$ & $292.593,82$ & $277.666,28$ & $1.371 .941,45$ \\
\hline IBIRAPITANGA & $233.969,65$ & $233.048,08$ & $315.334,26$ & $316.502,51$ & $271.500,83$ & $1.370 .355,33$ \\
\hline URUÇUCA & $228.972,62$ & $249.258,82$ & $286.388,92$ & $298.657,08$ & $295.415,87$ & $1.358 .693,31$ \\
\hline DOM BASÍLIO & $253.772,67$ & $269.078,25$ & $315.395,82$ & $280.311,69$ & $214.994,28$ & $1.333 .552,71$ \\
\hline MALHADA & $270.541,62$ & $228.540,30$ & $240.788,89$ & $261.085,68$ & $279.395,01$ & $1.280 .351,50$ \\
\hline UBAITABA & $224.977,39$ & $255.923,05$ & $288.664,16$ & $261.601,73$ & $236.403,40$ & $1.267 .569,73$ \\
\hline CONCEIÇÃO DO TOCANTINS/TO & $136.762,20$ & $149.127,73$ & $319.831,18$ & $403.134,58$ & $223.346,44$ & $1.232 .202,13$ \\
\hline UBATÃ & $210.220,86$ & $216.139,92$ & $249.893,23$ & $254.079,23$ & $250.265,86$ & $1.180 .599,10$ \\
\hline MANOEL VITORINO & $197.520,68$ & $213.651,75$ & $243.312,05$ & $255.387,78$ & $252.238,17$ & $1.162 .110,43$ \\
\hline ARACATU & $165.976,18$ & $178.897,82$ & $201.437,77$ & $214.318,18$ & $219.576,83$ & $980.206,78$ \\
\hline IRAMAIA & $173.391,45$ & $175.930,41$ & $198.965,20$ & $207.173,19$ & $205.769,87$ & $961.230,12$ \\
\hline AURELINO LEAL & $152.514,95$ & $165.239,56$ & $200.157,13$ & $210.568,71$ & $192.328,52$ & $920.808,87$ \\
\hline JITAÚNA & $142.805,78$ & $164.457,19$ & $193.858,07$ & $200.328,87$ & $196.822,13$ & $898.272,04$ \\
\hline LAGOA REAL & $148.909,94$ & $160.168,01$ & $179.615,19$ & $184.838,77$ & $180.560,73$ & $854.092,64$ \\
\hline RIO DO ANTONIO & $142.705,45$ & $152.940,82$ & $175.639,94$ & $183.816,71$ & $178.848,51$ & $833.951,43$ \\
\hline ITAGI & $144.994,84$ & $155.860,16$ & $180.623,83$ & $180.364,95$ & $167.095,35$ & $828.939,13$ \\
\hline MIRANTE & $137.734,01$ & $148.008,28$ & $169.760,63$ & $174.671,04$ & $170.923,92$ & $801.097,88$ \\
\hline IBIASSUCÊ & $124.039,53$ & $132.970,90$ & $154.850,49$ & $162.576,90$ & $154.436,28$ & $728.874,10$ \\
\hline MATINA & $124.229,28$ & $134.244,56$ & $152.244,92$ & $159.185,91$ & $158.815,20$ & $728.719,87$ \\
\hline CONTENDAS DO SINCORÁ & $118.354,79$ & $129.100,06$ & $149.545,77$ & $156.157,99$ & $153.611,65$ & $706.770,26$ \\
\hline BARRO PRETO & $112.171,26$ & $122.952,71$ & $142.907,19$ & $146.739,67$ & $143.412,71$ & $668.183,54$ \\
\hline BARRA DO ROCHA & $111.967,19$ & $123.790,04$ & $146.803,34$ & $140.470,01$ & $127.919,23$ & $650.949,81$ \\
\hline GONGOGI & $105.651,78$ & $116.352,43$ & $135.836,57$ & $133.509,65$ & $122.426,89$ & $613.777,32$ \\
\hline AIQUARA & $101.281,37$ & $109.323,18$ & $123.758,82$ & $121.197,20$ & $113.037,53$ & $568.598,10$ \\
\hline Total BA - 55 municípios (R\$) & 41.971.654,12 & 46.715.382,90 & $52.603 .606,80$ & 55.096.217,27 & $58.852 .005,69$ & $255.238 .866,78$ \\
\hline Total TO - 16 municípios (R\$) & $5.113 .841,98$ & $6.603 .690,06$ & $10.825 .633,11$ & $9.986 .941,08$ & $9.554 .600,07$ & 42.084.706,30 \\
\hline Total $(\mathbf{R} \$)$ & 47.085.496,10 & 53.319.072,96 & $63.429 .239,91$ & 65.083.158,35 & $68.406 .605,76$ & 297.323.573,08 \\
\hline
\end{tabular}


Num recorte dos 55 municípios baianos que serão impactados pela FIOL, o volume total de ICMS-E estimado para o período de 2016 até 2020 foi superior a 255 milhões. A cidade de Luís Eduardo Magalhães apresenta um maior destaque com 34 milhões de reais. Essa cidade possui uma população estimada em 92.671 pessoas, como poderá ser observado na Figura 3, sendo a $7^{\text {a }}$ colocada em número de tamanho populacional no estado da Bahia, (IBGE, 2020). Segundo a Confederação Nacional de municípios (CNM, 2021) a cidade apresenta um plano municipal para os resíduos sólidos próprio. A presença de lixões em outros municípios do entorno da FIOL demonstra a importância desse estudo para munir os entes municipais de mais recursos para fomentar a construção de aterros sanitários ou implantação de tecnologias mais avançadas no tocante à disposição dos resíduos sólidos.

São Desiderio apresentou a segunda posição, com 27 milhões de reais. Possui uma população de 34.764 pessoas (Figura 3), ocupando a $100^{\mathrm{a}}$ posição, consoante dados do IBGE (2020). Não possui um plano municipal para a gestão de resíduos sólidos (CNM, 2021).

A cidade de Barreiras ficou em quarto lugar, com uma estimativa calculada de ICMS-E em 22 milhões de reais. Possui a disposição de resíduos sólidos e plano municipal (CNM, 2020). Neste cenário a Figura 3 apresenta o traçado da FIOL com a população dos 55 municípios baianos envolvidos com a ferrovia, conforme o Instituto Brasileiro de Geografia e Estatística (IBGE, 2019).

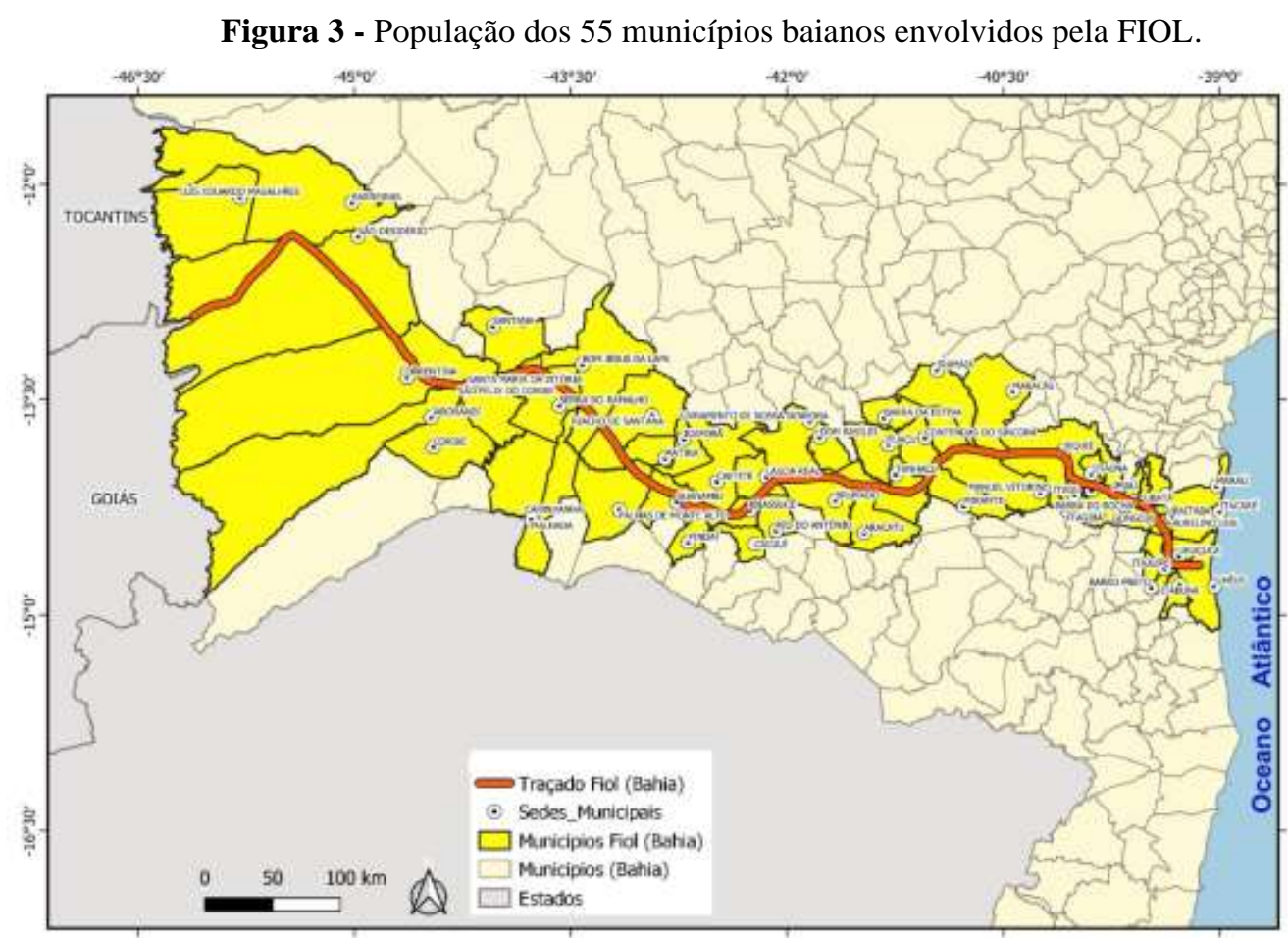

Fonte: RIMA (Ministério dos Transportes, 2009b) e IBGE (2019). Elaboração própria.

Foi possível constatar que os municípios de Ilhéus ( $6^{\circ}$ colocado), Itacaré ( $42^{\circ}$ colocado) e Uruçuca $\left(50^{\circ}\right.$ colocado), somaram no período entre 2016 até 2020, o montante superior a 22 milhões de reais. Segundo o CNM (2021), os referidos municípios não possuem um plano municipal para os resíduos sólidos.

É imperioso salientar que a presença de lixões e aterros não tecnicamente controlados nos municípios baianos, demostra a necessidade de investimentos conforme as adequações da Política Nacional de Resíduos Sólidos (PNRS) e a Política Estadual de Resíduos Sólidos (PERS/BA). Os cálculos demostrados permitem fazer menção de quanto os municípios poderiam ter recebido para a gestão de seus resíduos sólidos. 
Por sua vez, o município com maior arrecadação de ICMS-E no estado de Tocantins foi Ponte Alta do Bom Jesus, sendo o décimo segundo colocado com valor superior a 5 milhões e trezentos mil reais. O valor médio dos municípios tocantinenses é aproximadamente dois milhões e setecentos mil reais. Neste contexto, 39 municípios, ou cerca de 70\% do total, possuem um acumulado de arrecadação do ICMS-E abaixo de 2 milhões de reais.

\section{Possível Aplicação de Recursos do ICMS-E nos Gastos com Aterros Sanitários na Bahia}

Em posse dos valores estimados de ICMS-E, no período de 2016 até 2020, foi desenvolvida uma simulação para investimento do ICMS-E em aterros sanitários para os municípios baianos, tendo como base a capacidade e necessidade da gestão adequada no tratamento de resíduos sólidos, considerando a manutenção do aterro sanitário por ano.

Para fins de cálculos, os valores foram avaliados conforme estudos realizados pela Fundação Getúlio Vargas (FGV, 2008), posteriormente reavaliado pela Fundação Instituo de Pesquisas Econômicas (FIPE, 2017) e atualizada pelo Sindicato Nacional das Empresas de Limpeza Urbana (SELURB, 2020), que estima o preço (reais em média) do tratamento de 1 tonelada por um aterro considerado de grande porte com tratamento diário de $2000 \mathrm{t}$. A taxa de 2020 foi estimada de R\$ 104,16 (cento e quatro reais e dezesseis centavos).

Nesse cenário, os dados da simulação mostram o custo médio por toneladas (t) em reais de R\$104,16. Assim, utilizando o valor estimado na arrecadação de 2016 até 2020, o estado da Bahia teria recebido mais de 1,7 bilhões de reais de ICMS-E, o que possibilitaria tratar mais de 16,4 milhões de toneladas rejeitos, conforme Tabela 3.

Tabela 3 - Estimativa de quantidades em toneladas processas por unidade de aterros 2000T/dia para Bahia.

\begin{tabular}{c|c|c|c}
\hline ICMS-E/ANO BAHIA & $\begin{array}{c}\text { CUSTO MÉDIO / } \\
\text { toneladas }\end{array}$ & $\begin{array}{c}\text { TOTAL DE ICMS-E (R\$) } \\
\text { /ANO }\end{array}$ & $\begin{array}{c}\text { QUANTIDADE EM t } \\
\text { TRATADAS }\end{array}$ \\
\hline 2016 & 104,16 & $294.673 .947,50$ & 2.829 .051 \\
2017 & 104,16 & $316.460 .088,25$ & 3.038 .211 \\
2018 & 104,16 & $357.552 .961,93$ & 3.432 .728 \\
2019 & 104,16 & $372.638 .094,01$ & 3.577 .555 \\
2020 & 104,16 & $372.583 .438,83$ & 3.577 .030 \\
TOTAL & - & $\mathbf{1 . 7 1 3 . 9 0 8 . 5 3 0 , 5 2}$ & $\mathbf{1 6 . 4 5 4 . 5 7 5}$ \\
\hline
\end{tabular}

Fontes: FGV (2008), FIPE (2017), SELURB (2020), SEFAZ/BA (2021). Elaboração própria.

Aproveitando o desenvolvimento da FIOL, esses valores tendem a subir, em decorrência do possível aumento na circulação de mercadorias. Assim, cabe salientar que o estado tem avançado nos últimos anos, apresentando legislações voltadas para os resíduos sólidos, contudo ainda não implementou o ICMS-E, o que poderia propiciar um incremento de receitas aos municípios baianos em consonância a estimativa posta.

\section{Resultado da Discussão}

A análise dos resultados apresentados nos itens anteriores, sobretudo a seção 6, recomenda a adoção do ICMS-E na Bahia, o qual, quando aplicado ao entorno da FIOL, resultará em benefícios palpáveis. No estado, desde 1999, apenas se manteve em discussão a possibilidade de implementação do ICMS-E, quando foi proposto o ICMS Cidadão, trazendo no seu rol taxativo, dentre outros critérios, a conservação da biodiversidade. Novas tratativas para implementação do ICMS-E surgiram em 2006, por meio dos projetos de lei complementar estadual de $\mathrm{n}^{\circ} 76 / 2006$ e $\mathrm{n}^{\circ}$ 15.502/2006, sendo que a primeira proposta previu o critério ambiental de 5\%, distribuído da seguinte forma: 50\% para os municípios que dispusessem de sistema de tratamento, disposição final de lixo ou de esgoto sanitário, devidamente licenciado pelo órgão estadual competente, e o restante repassado, através do Índice de Conservação Municipal, que abrangeria as Unidades de Conservação. 
De outro turno, o segundo projeto replicou os $5 \%$ de repasse para os mesmos critérios ambientais, apenas exigindo que as unidades de conservações beneficiadas estivessem sujeitas ao determinado na Lei Federal n. 9.985/2000, que estabelece em seu art. $1^{\circ}$ o sistema nacional de unidades de conservação da natureza, in verbis: Art. $1^{\circ}$. Esta Lei institui o Sistema Nacional de Unidades de Conservação da Natureza (SNUC), que estabelece critérios e normas para a criação, implantação e gestão das unidades de conservação. Todavia, mais uma vez, não passou de mera conjectura a criação de critério ambiental para repasse do ICMS-E, não prosperando nenhum dos projetos sobre o tema, estando a questão na atualidade fora de pauta.

\section{Conclusão}

Com base nos dados verificados e qualificados em campo próprio, os sistemas ecológicos envolvidos no contexto de inserção da ferrovia são complexos e influenciados pelos biomas da Mata Atlântica, Cerrado e Caatinga.

Diante da complexidade dos sistemas naturais e da necessidade de instalação de ferrovia para a circulação das operações de mercado, é possível conciliar o uso do terreno com formas de proteção que garantam a preservação do ambiente natural, bem como a manutenção do mesmo.

Verificou-se que o uso das ferrovias possibilita maior acesso de áreas de longa distância, integrando grandes centros comerciais e facilitando o escoamento dos produtos produzidos no território. Não se pode olvidar que se trata de um dos modais de transporte de carga com menor custo e maior agilidade. Outro ponto positivo apresentado é que as ferrovias geram menos impactos ambientais comparados com outros modais de transporte. Esse fato é importante, pois a poluição no mundo e no Brasil tem aumentado com os anos e é uma das causas do aquecimento global.

Foram demonstrados os prováveis ganhos oriundos do ICMS-E para os municípios envolvidos na FIOL, referentes aos anos de 2016 até 2020. Considera-se que através da implementação deste instrumento de política pública, promove-se a obtenção de receitas para investimentos em prol da proteção das águas, solo, na criação de aterros sanitários, sendo o mesmo factível, sobretudo, para à proteção da biodiversidade. Sob essa perspectiva, o presente ensaio apresenta uma importante valoração do ICMS-E cuja parcela destinada para cada município, possibilitará um amplo programa de implantação de aterros sanitários ou de tecnologias mais avançadas de disposição de resíduos sólidos.

Cabe ressaltar que se comprovou que, malgrado o ICMS-E tenha se revelado um instrumento de política pública de sucesso, ainda não houve vontade legislativa local, existindo um grande vácuo no que se refere aos motivos de sua não implementação na Bahia.

Aventa-se o interesse em aprofundar os estudos acerca dos entraves que ensejaram a não implementação do ICMS-E na Bahia, ainda que a Constituição Federal (Brasil, 1988) determine que parte do recebido pelos municípios de ICMS possam ser atribuídos para uso em critérios ambientais, sugerindo-se, assim, a temática, para vindouro artigo.

Por fim, o ICMS-E apresenta-se como uma alternativa viável para os investimentos diretos do poder público nas questões ambientais, e como não existe fronteiras para conservação da biodiversidade, a implementação deste instrumento de política pública poderá proporcionar aos municípios pertencentes ao traçado da FIOL Bahia, incrementos financeiros consideráveis, desde que fomentem a conservação da natureza em benefício de toda sociedade.

\section{Agradecimentos}

O presente trabalho foi realizado com apoio da Coordenação de Aperfeiçoamento de Pessoal de Nível Superior Brasil (CAPES) e da Fundação de Amparo à Pesquisa do Estado da Bahia (FAPESB). 


\section{Referências}

ABRELPE - Associação Brasileira de Empresas de Limpeza Pública e Resíduos Especiais. (2020). Panorama 2020. https://abrelpe.org.br/panorama.

ANTF - Associação Nacional dos Transportadores Ferroviários. (2021). Informações Gerais. https://www.antf.org.br/informacoes-gerais/.

Baiardi, A. (2015). Potencial de Agricultura Sustentável na Bahia. Editora da Universidade Federal da Bahia. 1. 173p.

Baiardi, A. \& Teixeira, F. (2010). O desenvolvimento dos territórios do Baixo Sul e do Litoral Sul da Bahia: a rota da sustentabilidade, perspectivas e vicissitudes. Salvador: Instituto Arapyaú.

Bobbio, N.; Mateucci, N. \& Pasquino, G. (2004). Dicionário de política. (2 volumes). Editora UnB.

Borges, L. A. C.; de Rezende, J. L. P. \& Pereira, J. A. A. (2009). Evolução da Legislação Ambiental no Brasil. Revista em Agronegócio e Meio Ambiente, 2(3), 447-466.

Brasil. (1966). Código Tributário Nacional. Lei no 5.172, de 25 de outubro de 1966. Dispõe sobre o Sistema Tributário Nacional e institui normas gerais de direito tributário aplicáveis à União, Estados e Municípios. http://www.planalto.gov.br/ccivil_03/leis/15172.htm.

Brasil. (1965). Lei $n^{\circ}$ 4.771, de 15 de setembro de 1965. Institui o novo Código Florestal. Brasília, DF: Presidência da República, 15 de setembro de 1965; $144^{\circ}$ da Independência e $77^{\circ}$ da República. Este texto não substitui o publicado no DOU de 16.9 .1965 e retificado em 28.9 .65 . http://www.planalto.gov.br/ccivil_03/leis/14771impressao.htm.

Brasil. (1981). Lei $n^{\circ}$ 6.938, de 31 de agosto de 1981. Dispõe sobre a Política Nacional do Meio Ambiente, seus fins e mecanismos de formulação e aplicação, e dá outras providências. http://www.planalto.gov.br/ccivil_03/Leis/L6938.htm.

Brasil. (1988). Constituição da República Federativa do Brasil de 1988. http://www.planalto.gov.br/ccivil_03/Constituicao/Constituicao.htm

Brasil. (2002). Lei n. 12.206 de 2002. ICMS Ecológico. Câmara Legislativa Estadual.

Brasil. (2010). Lei $n^{\circ}$ 12.305/2010, de 2 de agosto de 2010. Institui a Política Nacional de Resíduos Sólidos; altera a Lei no 9.605, de 12 de fevereiro de 1998; e dá outras providências. http://www.planalto.gov.br/ ccivil_03/_ato2007-2010/2010/lei/112305.htm.

Brasil. (2014). Lei $n^{o}$ 12.932/2014, de 7 de janeiro de 2014. Institui a Política Estadual de Resíduos Sólidos, e dá outras providências. http://www.legislabahia.ba.gov.br/documentos/lei-no-12932-de-07-de-janeiro-de-2014.

Brasil. (2015). Lei n. 2.959 de 2015. ICMS Ecológico. Câmara Legislativa Estadual.

Brasil. Instituto do Meio Ambiente e Recursos Hídricos. (2021). Parque Estadual da Serra do Conduru.

CMMAD - Comissão Mundial Sobre Meio Ambiente e Desenvolvimento. (1998). Nosso futuro comum. Fundação Getúlio Vargas.

CMN - Confederação Nacional dos Municípios. (2021). Observatório do lixo. http://www.lixoes.cnm.org.br/.

Derry, T. K. \& Williams, T. I. (1993). A short history of technology from the earliest times to AD 1900. Dover Publication.

FGV - Fundação Getúlio Vargas. (2008). Relatório Final. Estudo sobre os Aspectos Econômicos e Financeiros da Implantação e operação de Aterros Sanitários. Disponível em: https://abetre.org.br/publicacoesabt.

Franklin, B. \& Franklin, W. T. (1817). The Private Correspondence of Benjamin Franklin (2a ed.). Printed by A. J. Valpy. p.266.

FIPE - Fundação Instituto de Pesquisas Econômicas. (2017). Relatório Final. Estudo sobre os Aspectos Econômicos e Financeiros da Implantação e operação de Aterros Sanitários. https://selur.org.br/wp-content/uploads/2017/06/FIPE-RELAT\%C3\%93RIO-ASPECTOS-ECONOMICO-FINANCEIROSATERROS.pdf.

Galeski, I. Junior. (2007). O sistema tributário sustentável, o desenvolvimento e a cidadania: em busca do equilíbrio. Revista Jurídica, 20(4), 49-75.

Gil, A. C. (2002). Como elaborar projetos de pesquisa. (4a ed.). Atlas.

IBGE - Instituto Brasileiro de Geografia e Estatística. (2013). Hidroquímica dos Mananciais Subterrâneos - Região Nordeste. https://cidades.ibge.gov.br.

IBGE - Instituto Brasileiro de Geografia e Estatística. (2019). Estimativa da população. https://ibge.gov.br.

IBGE - Instituto Brasileiro de Geografia e Estatística. (2020). Cidades. https://cidades.ibge.gov.br/brasil/ba/panorama.

IBGE - Instituto Brasileiro de Geografia e Estatística. (2021). Portal. https://ibge.gov.br.

IMA/AL - Instituto do Meio Ambiente do Estado do Alagoas. (1986) Resolução $n^{\circ}$ 001/1986. http://www.ima.al.gov.br/wizard/docs/RESOLU\%20C ONAMA\%20N001.1986.pdf.

INEMA - Instituto do Meio Ambiente e Recursos Hídricos. (2021). Parque Estadual da Serra do Conduru. http://www.inema.ba.gov.br/gestao-2/unidades-deconservacao/parque-estadual/parque-estadual-da-serra-do-conduru.

Malhotra, N. K. (2001). Pesquisa de marketing: uma orientação aplicada. Tradução Nivaldo Montingelli Júnior e Alfredo Alves de Farias (3a ed.). Bookman. 
Mendes, M. J. (2008). Sistema orçamentário brasileiro: planejamento, equilíbrio fiscal e qualidade do gasto público. Brasília: Consultoria Legislativa do Senado Federal.

Ministério dos Transportes. (2009a). Relatório de impacto ambiental da Ferrovia Oeste-Leste (EF- 334) entre Figueirópolis (TO) e Ilhéus (BA). Brasília: Valec Engenharia, Construções e Ferrovias S.A.

Ministério dos Transportes. (2009b). Relatório de Impacto Ambiental - RIMA: Ferrovia de Integração Oeste - Leste (EF-334) entre Figueirópolis (TO) e Ilhéus (BA). https://www.ilheus.ba.gov.br/abrir_arquivo.aspx/RIMA_(FERROVIA_DE_INTEGRACAO_OESTE-LESTE)?cdLocal=2\&arquivo=\%7B8EED021CA427-1EAC-DB2A-B4C6B73BC01E\%7D.pdf.

ONU - Organização das Nações Unidas. (1992). Relatório da conferência das Nações Unidas sobre Meio ambiente e Desenvolvimento. A/ CONF.151/26. Declaração de Princípios sobre Florestas. http://www.meioambiente.pr.gov.br/arquivos/File/agenda21/Declaracao_de_Principios_sobre_Florestas.pdf.

ONU - Organização das Nações Unidas. (2010). Direito Humano à Água e ao Saneamento: resolução da Assembléia Geral n64/292. Nova Iorque: Assembléia Geral, A/RES/64/292.

Rêgo, C. J. F. (2013). Equilíbrio fiscal no Brasil. [Monografia de Especialização, Pós-graduação em Direito Tributário e Finanças Públicas, Instituto Brasileiro de Ensino, Desenvolvimento e Pesquisa, Natal]. https://repositorio.idp.edu.br//handle/123456789/3412.

Rios, E. P. \& Thompson, M. (2013). Biomas brasileiros. Melhoramentos.

Santos, R. S. do. (2004). O encanto da lagoa: o imaginário histórico-cultural como elemento propulsor para o turismo cultural na Lagoa Encantada. [Dissertação, Mestrado em Cultura \& Turismo Universidade Estadual de Santa Cruz), Brasília.

SEFAZ/BA - Secretaria da Fazenda do Estado da Bahia. (2021). Repasse aos Municípios. https://www.sefaz.ba.gov.br/administracao/contas/menu_repasse.htm.

SEFAZ/TO - Secretaria da Fazenda do Tocantins. (2021). Desempenho do ICMS-Ecológico - comparativo por município. Índice de participação dos municipios. http://www.sefaz2.to.gov.br/repasses/icmsecologico.php.

SELURB - Sindicato Nacional das Empresas de Limpeza Urbana (2020). Índice de Sustentabilidade da Limpeza Urbana - ISLU. https://selur.org.br/wpcontent/uploads/2021/05/ISLU-2020-a.pdf.

SIMEFRE - Sindicato Interestadual da Indústria de Materiais e Equipamentos Ferroviários e Rodoviários. (2013). Boletim econômico. https://simefre.org.br.

Sobral, R. R., Neto \& Reis, R. B. (2020). ICMS ecológico: a experiência de alguns estados brasileiros e possibilidades para o Estado da Bahia. Research, Society and Development, 9(11), e3729119738-e3729119738. DOI: 10.33448/rsd-v9i11.9738. https://rsdjournal.org/index.php/rsd/article/view/9738.

TCE-PE - Tribunal de Contas do Estado de Pernambuco. (2021a). Relatório sobre resíduos sólidos no estado em 2020. https://www.tce.pe.gov.br/internet/index.php/estudos-e-levantamentos-novo.

TCE-PE - Tribunal de Contas do Estado de Pernambuco. (2021b). Repasse do ICMS Ecológico. https://www.tce.pe.gov.br/internet/index.php/repasse-do-icmsecologico.

Tischer, V. (2018). Panorama do transporte ferroviário urbano no Brasil e no mundo. Revista Internacional de Ciências, 8(1), 62-81.

UNESCO \&COMEST. (2001). A ética do uso da água doce. Edições UNESCO Brasil. 